\title{
Consideration of Factors Related to Arm Wrestling Strength by Mechanical Analysis
}

\author{
Hideo Hirai* \\ Faculty of Health Sciences, Hiroshima Cosmopolitan University, Hiroshima, Japan
}

*Corresponding author: Hideo Hirai, Department of Rehabilitation, Hiroshima Cosmopolitan University, Japan.
Received Date: April 10, 2020

Published Date: April 20, 2021

\section{Opinion}

Since ancient times, arm wrestling has been practiced among various people because it can be easily performed by anyone without specialized knowledge or skills.

As for the history of arm wrestling, "Kojiki" has the oldest description of arm wrestling, and "Gikeiki" in the Muromachi period also has a description of arm wrestling. In 1928, Mr. Satoshi Yamamoto founded the "Yokohama Udenokai Association", and in 1950 the name was changed to "Japan Arms Wrestling Association", and the activity is still active.

On the other hand, it is also held as international competition under strict rules and regulations. The arm-wrestling competition in Japan was born in 1977 as the "Japan Arm Wrestling Federation" that set formal rules and joined the World Arm Wrestling Federation in 1987. In today's health-conscious society, arm wrestling is thus widespread among people as play or competition. In research on arm wrestling, there are many studies that reproduce the movement of arm wrestling in order to generalize the robotics in various ways or injuries that occurred during arm wrestling.

There are two types of robotics research: research on wearable robots that are intended to be operated by humans, and research on systems as interpersonal arm-wrestling robots. Studies on injuries during arm wrestling show that the area of the arm that is prone to injury during arm wrestling is limited.

But there are few studies that mechanical analyze the movement or movement of an actual human being during arm wrestling. From a mechanical point of view, arm wrestling is adapted to the third lever. With the third lever, the shorter the lever arm from the fulcrum to the force point, the stronger the force can be exerted at the point of action. In the case of arm wrestling, the fulcrum is the elbow head, the force point.

Mechanical analysis of arm-wrestling Opinion is the forearm attachment part of the biceps brachii, and the lever arm corresponds to this length. In this case, the part of the hand that grips the opponent is the point of action, so how much power can be exerted here will determine the outcome. Therefore, it can be expected that factors such as lever arm length, arm strength, and weight are the keys to the strength of arm wrestling.

We would like to study how these factors actually relate to the strength of arm wrestling. Therefore, we would like to dynamically analyze the human movement during actual arm wrestling and utilize them in methods and training to win.

\section{Conclusion}

Mechanically analyze arm wrestling and investigate the relationship between various factors and the strength of arm wrestling.

\section{Acknowledgement}

None.

\section{Conflicts of Interest}

No conflicts of interest. 